\title{
The Difference Between Leadership And Management: A Gender Perspective
}

\author{
Shahid D. Siddiqui \\ Department of Leadership Management Studies \\ National Defence University \\ Islamabad
}

\begin{abstract}
Discussions on leadership typically get bogged down by a debate between the differences of leadership and management. Some authors argue that leadership and management are diametrically opposed concepts (Bennis \& Nanus, 1985) while other authors use the terms interchangeably (Yukl, 2010). This article consider competing perspectives to understand better the relationship between leadership and management, and will conclude by suggesting that effective leaders need to be good managers and that effective managers need to be good leaders. In leadership and management the gender perspective is of outstanding importance. This article also explains that women's traditional and stereotypic styles of communication are more like those of a good manager than are men's stereotypic styles.

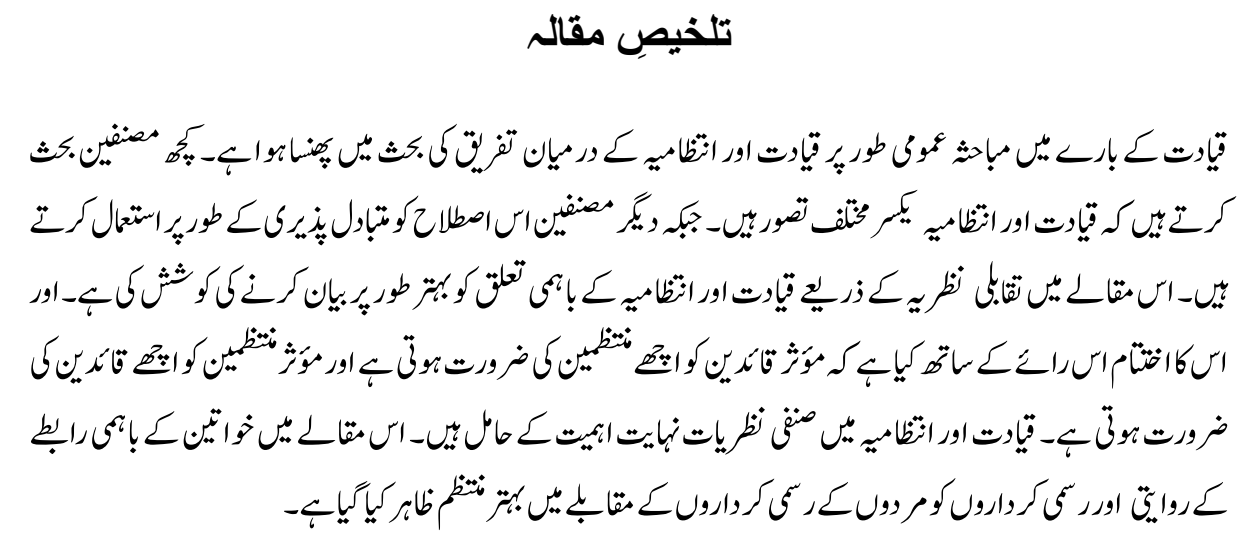

What is the difference between leadership and management? It is a frequently asked question and that has been answered in different ways. Usually the terms used interchangeably, but there is a difference. Beside the definitions of the terms, there is a real, practical, and meaningful differentiation.

Management is planning and organizing projects and operations, allocating resources to minimize costs and maximize benefits, directing practices and procedures, establishing controls to measure the effectiveness and efficiencies, and motivating subordinates. Management is concerned with present activities and the immediate results of those activities. Whereas Leadership is more abstract when considered separately from management. Leadership is guiding a person or group toward the best results. It is having 
sound understanding to determine and ability to articulate visions and goals. Leadership is in par with management, but takes on precedence for strategic management and longterm success.

Stephen Covey used a ladder to illustrate the difference between leadership and management in his book, 7Habit of Highly Effective People. Management is concerned with getting up a ladder in the most effective and most efficient manner. Leadership is making certain the ladder is on the right wall. Covey makes it clear that an individual must make a paradigm shift before incorporating these habits into his/her own personal life. Covey emphasizes that if we want to make a change in our lives, we should probably first focus on our lives, we should probably first focus on personal attitudes and behaviours. He applies different examples via family, business, and society in general. (Covey, 2004)

I have also heard management is focused internally within an organization or group, while leadership is focused externally toward the industry and the market place. However, you chose to define the difference, when you understand the difference, you will be a better manager and better leader.

\section{Leaders and Managers are Different}

Introducing the expression "managers are people who do things right, and leaders are people who do the right thing", Bennis and Nanus (1985) asserted that an individual cannot be both a leader and a manager because leaders and managers have fundamentally different values and personalities. This encapsulated the classic distinction that implies that leaders are inherently good while managers are essentially cold-hearted (Zaleznik, 1977). This perspective sees the manager as stable, orderly, efficient, impersonal, risk averse, and short-term focused. In comparison, leaders are flexible, innovative, adaptive, caring, and long-term focused.

Although scholars and professionals alike quote the Bennis and Nanus (1985) definition to the point of cliché, it has serious limitations, as follows:

- First, empirical research has failed to support the mutual exclusivity of leadership and management (Yukl, 2010).

- Second, the perspective demonstrates ignorance of contemporary management writings, which almost universally consider leadership as one of the fundamental functions of management, along with planning, organizing, and controlling (Bateman \& Snell, 2007; Nickles, McHugh, \& McHugh, 2010). In other words, contemporary management scholarship and practice present leadership as a fundamental function of management—not as a mutually exclusive concept. Meanwhile, leadership literature 
is also starting to recognize the importance of effective management as a component of effective leadership (Yukl, 2010).

- Third, Yukle asserted that Benis and Nanus presented "extreme stereotypes" (p. 7) that denigrate managers by implying that they are calculating and unethical fiends who cannot do the right thing. The same stereotype approach elevates leaders as effective, saintly beings who cannot do things right.

- Fourth, reversing the Bennis and Nanus logic exposes a fundamental flaw in their argument: if "managers are people who do things right and leaders are people who do the right thing," then it follows that managers are people who cannot do the right thing while leaders are people who cannot do things right [See Table 1: Interpretation of the Bennis and Nanus stereotype of leaders and managers]. Similarly, if leaders are people who do the right thing and Hitler was a leader to the German people, then, according to the Bennis and Nanus reasoning, Hitler did the right thing. Granted, some contemporary scholars hold the idealistic position that only a person who influences others to do good things can be considered a leader, so Hitler was not a leader; but this trivializes the affect that "good" and "bad" leaders can have on individuals, societies, and civilizations.

- Finally, some authors propose that one is not better than the other; both leadership and management serve different roles for accomplishing the same purpose (Hughes, Ginnett, \& Curphy, 2005). For example, considering a stereotypical leader may inspire and motivate people; but without the structure and process provided by the stereotypical manager, inspiration may not be enough to organize and focus collective energy toward common goals.

\section{Leaders and Managers are not Different}

Other scholars have varying definitions of leadership and management but "do not assume that the leader and the manager are different people" (Yukl, 2010, p. 7). Mintzberg (1973, in Yukl, 2010) argued that the leadership role pervades all other managerial roles. Kotter (1990) saw management as a process for creating order and predictability, and leadership as a process for driving changes. Though he saw them as different functions, Kotter argued that both are necessary and that the situation determines the proper balance of leadership and management. For example, smaller organizations might need a larger infusion of leadership; but as they grow they need more management. The more dynamic and uncertain the external environment, the more leadership becomes necessary for driving continuous adaptation and transformation.

From a managerial perspective, Gary Dessler (2002) proposed that a leader is a person with managerial and personal power who can influence others to willingly perform actions and achieve goals beyond what the followers could achieve on their own. The manager's influence is limited by the authority of the position and the ability to reward 
and punish people for progressing toward organizational goals. The key difference Dessler suggests is in motivating others to perform willingly versus rewarding and punishing people to perform. Though different applications of power, Dessler argues that leadership and management must be intertwined to be effective. Without influence and inspiration from leadership, organizing and planning may be ineffective. Similarly, regardless of how inspirational a leader may be, management proficiencies and functions are necessary for planning, structuring, and controlling of human activity.

\section{Leadership and Management are Interchangeable}

Some authors put aside the differences between management and leadership, and use the terms interchangeably because managers are "people who occupy positions in which they are expected to perform a leadership role" (Yukl, 2010, p. 8). Managers assert influence over people and processes; as far as leadership is an influence process, managers serve a leadership role. The manager's ability to perform the functions of his or her job-planning, organizing, and controlling activities toward common goals--can be limited by his or her ability to influence people and processes. Similarly, a leader's effectiveness may be limited by his or her ability to plan, organize, and control human activity toward common goals.

\section{Small Changes Make a Big Difference}

While discussing the difference between leadership and management one can not overlook the gender perspective as Gender discussions often tend to become very emotional and can make the difference (Bathon, Joan, 2008). We have to understand that both men and women operate under the same beliefs. Gender barriers are similar across disciplines and probably across cultures. Gender schemas are subconscious and many decisions are unfortunately based on these schemas. But it is hard to see the invisible barriers, the "glass ceiling" and the "sticky floor", When you work with gender you will often be told not to make a mountain out of a molehill, but many molehills add up to a mountain. All these "small" things, like women being interrupted more often than men, jokes and negative comments about women, the informal male networking, etc, actually add up and form a pattern.

It is also found that one of the more obvious reasons for women not making it to the top was that they simply were not nominated for promotion by their division or departmental chiefs. - The leadership structure in the world is still anachronistic and progress is rather slow but it also suggests that start to create changes within your own institution, show new examples of leadership, encourage an overall gender awareness and remember that very small differences in treatment can result in large disparities in salary and promotion over time. 


\section{Gender Awareness Necessary for Good Leadership and Management}

Today's leadership model is male but we are in a period of big change now. The weakest leaders are those who are afraid of women.

(Dahlbom-Hall, Barbro,2008)

Culture, religion, race and social class are all very important but there is nothing that dominates your identity more than your gender. Gender concerns us all, men and women alike. Gender awareness is necessary for good leadership and management but unless you see the patterns from a deep individual level nothing will ever change. Barbro DahlbomHall stressed that gender awareness is about knowledge, not emotions. But working with gender is very threatening for both men and women. Gender is connected with control and power balance and very often there is a gender issue underneath a bitter conflict, not least in the medical/academic sector.

Gender conflicts hurt because they always have an emotional impact. Gender affects our personalities, behaviour and actions from the moment we are born. Bright girls talk a lot when they are about four years old. After that they usually are suppressed whereas little boys are encouraged to take space but on the other hand they are seldom allowed to show any feelings. To be praised a "real" girl has to be happy, smiling, obedient and loyal. She is allowed to be clever but never brilliant and she should never question anything. If women talk about 30 percent as much as men, the men - but also the women - usually get the impression that women are "taking over". To understand gender patterns is to be in a continuous process. Everything cannot be explained and it takes time, training and reflection to develop awareness. Barbro Dahlbom- Hall emphasized that for a leader and a manager it is important to see both your own individual pattern and the general pattern. There is not only one way to be a man or a woman.

Barbro Dahlbom-Hall stressed many times that society needs to be changed by women and men together, in a respectful dialogue. Today's leadership model is male but we are in a period of big change now. The weakest leaders are those who are afraid of women. Therefore it's important to work with and focus gender awareness training on men to prevent them from being so scared of women that they will try to stop them (Barbro Dahlbom-Hall, Barbro, 2008).

\section{Conclusion}

One has to find their own best way to integrate gender awareness in their identity and in their leadership. One must learn to lead themselves before they can lead others. And to become a successful leader one must learn how to deal with gender conflicts. Managers 
must have leadership competence, and leaders should have management skills--or the ability to engage others who can plan, organize, and control collective action toward the leader's vision. Platitudes that assert leadership and management are diametrically opposed concepts promote an inaccurate stereotype that tarnishes understanding of both while diminishing the potential effectiveness of those who adopt the axiom as a guiding philosophy.

\section{References}

Bateman, T. S., \& Snell, S. A. (2007) Management: Leading \& collaborating in a competitive world (7th ed.). New York, NY: McGraw-Hill Irwin.

Bathon, Joan ( 2008) Small Changes Make a Big Difference, www.autocure.org/news/joan bathon_article.htm), retrieved on 23-05-2011

Bennis, W., \& Nanus, B. (1985) Leadership: The strategies for taking charge. New York, NY: Harper \& Row.

Covey, Stephen R. (2004) (Revised edition) The 7 Habits of Highly Effective People, New York, Free Press

Dahlbom-Hall, Barbro (2008) Teaching men to live - the dilemma of leadership, www.autocure.org/news/barbro dahlbom hall_article.htm), retrieved on 23-052011

Dessler, G. (2002). Management: Theory, practice, and application (University of Phoenix Custom Edition ed.). Upper Saddle River, NY: Prentice Hall.

Hughes, R. L., Ginnett, R. C., \& Curphy, G. J. (2005) Leadership: Enhancing the lessons of experience (5th ed.). New York: McGraw-Hill.

Kotter, J. P. (1990). A force for change: How leadership differs from management. New York, NY: Free Press.

Mintzberg, H. (1973, in Yukl, 2010). The nature of managerial work. New York, NY: Harper \& Row.

Nickles, W. G., McHugh, J. M. \& McHugh, S. M. (2010) Understanding Business (9 $^{\text {th }}$ ed.) New York, NY: McGraw-Hill Irwin. 
Yukl, G. (2010). Leadership in organizations (7th ed.). New York, NY: Pearson Prentice Hall.

Zaleznik, A. (1977). Managers and leaders: Are they different? Harvard Business Review, 55 (5), 67-78.

Shahid D. Siddiqui is Lecturer in the Department of Leadership Management Studies, National Defence University, Islamabad. 